\title{
Procedures, placement, and risks of further abuse after Munchausen syndrome by proxy, non-accidental poisoning, and non-accidental suffocation
}

\author{
P Davis, R J McClure, K Rolfe, N Chessman, S Pearson, J R Sibert, R Meadow
}

\begin{abstract}
Objectives-To investigate outcome, management, and prevention in Munchausen syndrome by proxy, nonaccidental poisoning, and non-accidental suffocation.
\end{abstract}

Design-Ascertainment through British Paediatric Surveillance Unit and questionnaires to responding paediatricians. Setting-The UK and Republic of Ireland, September 1992 to August 1994.

Subjects-Children under 14 years diagnosed with the above.

Main outcome measures-Placement and child protection measures for victims and siblings; morbidity and reabuse rates for victims; abuse of siblings; prosecution of perpetrators.

Results-Outcome data for 119 with median follow up of 24 months (range 12 to 44 months). No previously diagnosed factitious disease was found to have been caused by genuine disease. Forty six children were allowed home without conditions at follow up. Children who had suffered from suffocation, non-accidental poisoning, direct harm, and those under 5 years were less likely to go home.

Twenty seven $(24 \%)$ children still had symptoms or signs as a result of the abuse at follow up; $108 / 120$ were originally on a child protection register and $35 / 111$ at follow up. Twenty nine per cent (34/118) of the perpetrators had been prosecuted and most convicted; $17 \%$ of the milder cases of Munchausen syndrome by proxy allowed home were reabused. Evidence in siblings suggests that in $50 \%$ of families with a suffocated child and $40 \%$ with non-accidental poisoning there would be further abuse, some fatal.

Conclusions-This type of abuse is severe with high mortality, morbidity, family disruption, reabuse, and harm to siblings. A very cautious approach for child protection with reintroduction to home only if circumstances are especially favourable is advised. Paediatric follow up by an expert in child protection should also occur.

(Arch Dis Child 1998;78:217-221)

Keywords: child abuse; Munchausen syndrome by proxy; poisoning; suffocation
Meadow coined the term Munchausen syndrome by proxy in 1977. In Munchausen syndrome by proxy a child is presented for medical attention, often repeatedly, with symptoms or signs of illness that have been fabricated by an adult carer, for that adult's benefit. Many cases of Munchausen syndrome by proxy involve poisoning or suffocation of the child. These problems can also be seen in isolation as manifestations of physical abuse. The overlap and similarities between cases justify discussing them collectively, as we have done in this study. ${ }^{1}$

We described the epidemiology of this spectrum of abuse in an earlier paper. ${ }^{1}$ The annual incidence of the condition was $0.5 / 100000$ for children under 16 years. There were 128 cases in two years in the British Isles, of which 97 cases involved Munchausen syndrome by proxy, 32 suffocation and 44 poisoning, with considerable overlap between the types of abuse. In our first paper we reported that sibling abuse occurred in 34 out of 83 families. We also reported 18 deaths in 15 of these 83 families.

Anecdotal evidence suggests that some cases of Munchausen syndrome by proxy are particularly difficult to manage, that legal approaches are inconsistent, and that outcomes are often suboptimal. Long delays in making the initial diagnosis increase the likelihood of a poor outcome. The frequent accompanying denial (both in parents and professionals) and family dynamics also support perpetrators in their denial. Perpetrators have an inherent skill in manipulating health workers and the child protection services. ${ }^{1-4}$

Meadow identified factors associated with greater danger to the child from his series. These included suffocation or poisoning, a child under 5 years, and previous sibling "cot deaths". Adverse features in the perpetrator included poor understanding, Munchausen's syndrome, drug or alcohol dependency, or persistence of fabrication after confrontation. ${ }^{5}$ Neale et al found that cases of Munchausen syndrome by proxy had the best outcome if taken into long term care at an early age without access to their mother. ${ }^{6}$ Victims subject to long term uncontrolled involvement with their mothers fared worst. McGuire and Feldman concluded that "Even with protection from further physical injury, severe psychological trauma remains likely. Extreme caution is suggested in allowing these children to remain in the family". 
Bools and his colleagues studied a number of selected cases looking at psychosocial morbidity and concluded that the adverse effects of Munchausen syndrome by proxy on children were more severe than expected. ${ }^{3}$ This included impairment of the child's physical, emotional, and educational development.

All this work came from cases based on referrals to expert centres. We are unaware of any studies of outcome on a population based cohort of children subjected to this type of abuse. We are therefore reporting further evidence from our study based on the whole population of children in the British Isles through the British Paediatric Surveillance Unit (BPSU). We aimed to identify the outcome of child protection in terms of placement, procedures, and reabuse rates, as well as the known clinical morbidity of the abuse. We did not undertake detailed assessment of individual children or perpetrators because of practical and ethical difficulties.

\section{Methods}

The paper describes the second phase of a collaborative study between researchers in Cardiff and Leeds. We have described previously the method by which we identified the cohort using the BPSU reporting scheme. ${ }^{1}$ The key inclusion criterion was that a formal child protection case conference had been held to

Table 1 Placement outcome for surviving index cases (eight died)

\begin{tabular}{llllll}
\hline & Initial placement & & \multicolumn{2}{l}{$\begin{array}{l}\text { Placement at follow up } \\
\text { (mean 24 months) }\end{array}$} \\
\cline { 2 - 3 } \cline { 5 - 6 } Abuse category & $\begin{array}{l}\text { No of cases } \\
\text { (excluding death) }\end{array}$ & $\begin{array}{l}\text { No returning } \\
\text { home }\end{array}$ & $\begin{array}{l}\text { No of cases } \\
\text { (excluding deaths) }\end{array}$ & No at home \\
\hline All cases & 120 & 34 & 111 & 46 \\
"Direct harm" & 78 & 10 & & 72 & 16 \\
No direct harm & 42 & 24 & 39 & 30 \\
\hline
\end{tabular}

Table 2 Placement outcome for different abuse categories

\begin{tabular}{|c|c|c|c|c|}
\hline Abuse category & $\begin{array}{l}\text { No of cases } \\
\text { (excluding } \\
\text { deaths) }\end{array}$ & $\begin{array}{l}\text { No returning } \\
\text { home after initial } \\
\text { episode }\end{array}$ & $\begin{array}{l}\text { No ascertained at } \\
\text { follow up (excluding } \\
\text { deaths) }\end{array}$ & $\begin{array}{l}\text { No at home } \\
\text { at follow up }\end{array}$ \\
\hline Suffocation & 28 & 0 & 26 & 3 \\
\hline Poisoning & 39 & 6 & 35 & 8 \\
\hline \multirow{2}{*}{\multicolumn{5}{|c|}{ Munchausen syndrome }} \\
\hline & 96 & 31 & 91 & 42 \\
\hline
\end{tabular}

Table 3 Placement outcome by age

\begin{tabular}{lllll}
\hline Age of victim & $\begin{array}{l}\text { No of cases } \\
\text { (excluding } \\
\text { deaths) }\end{array}$ & $\begin{array}{l}\text { No returning home } \\
\text { after initial episode }\end{array}$ & $\begin{array}{l}\text { No at follow up } \\
\text { (excluding deaths) }\end{array}$ & $\begin{array}{l}\text { No at home at } \\
\text { follow up }\end{array}$ \\
\hline Over 5 years & 28 & 14 & 25 & 14 \\
Under 5 years & 92 & 20 & 86 & 32 \\
\hline
\end{tabular}

Table 4 Summary of detailed placement information

\begin{tabular}{lll}
\hline Placement category & $\begin{array}{l}\text { No of cases } \\
\text { (excluding } \\
\text { deaths) } \\
\text { initially }\end{array}$ & $\begin{array}{l}\text { No at follow up } \\
\text { (mean 24 } \\
\text { months) }\end{array}$ \\
\hline All & 120 & 111 \\
Accommodated by the local authority & 46 & 36 \\
Returned home without major conditions & 34 & 46 \\
With relatives & 14 & 8 \\
$\begin{array}{l}\text { At home but subject to major conditions, usually the exclusion } \\
\text { of the perpetrator }\end{array}$ & 13 & 16 \\
Remained in hospital & 6 & 0 \\
Unknown & 7 & 4 \\
\hline
\end{tabular}

discuss one of these diagnoses. We obtained further information from paediatricians by an initial questionnaire.

Between September 1994 and August 1995 notifying paediatricians were again asked to complete a questionnaire concerning the outcome of their case. When the paediatrician was unable to provide full details the child's general practitioner, health visitor, or social worker was contacted. We made no direct contact with the child or family at any time. The follow up questionnaire requested details of the case including diagnostic certainty, placement of the child, child protection procedures, reabuse of index cases and siblings, ongoing morbidity as a result of abuse, and prosecution of perpetrators. We performed statistical analysis with $\chi^{2}$ test using Yates's correction.

\section{Results}

We identified 128 index cases in the original cohort. We obtained outcome data for 119: a response rate of $93 \%$. We were unable to obtain data on the remainder of cases because: type of abuse was in doubt (one case), no available information (four cases), and the paediatrician did not respond to follow up questionnaire (four cases).

The median duration of follow up (from the original case conference until the date of completion of the follow up questionnaire) was 24 months (range 12 to 44 months).

\section{CONFIRMATION OF DIAGNOSIS}

Notifying paediatricians expressed a high degree of certainty about their diagnoses of these conditions. We asked them in the follow up phase whether the diagnosis still stood (on balance of probability). We excluded only one case because of diagnostic uncertainty: a case where there was a clear diagnosis of neglect but the paediatrician did not think it was due to Munchausen syndrome by proxy. We found no previously diagnosed factitious illness to have been caused by genuine disease.

PLACEMENT OF VICTIMS

We investigated both the initial placement of the 120 surviving cases and the placement at follow up of the 111 surviving victims about whom we received information. The placement (numbers of children returned home without major conditions, for example perpetrator still present), categorised by type of abuse, is shown in tables 1-4. The differences between initial placement and follow up just did not reach significance $(\mathrm{p}<0.1)$.

\section{PLACEMENT OF SUFFOCATION AND}

NON-ACCIDENTAL POISONING CASES

Four of the 32 suffocation victims died (one of whom had also been poisoned). The 28 surviving children were treated significantly differently from the main body of cases of Munchausen syndrome by proxy in respect of placement. No child was allowed to return initially home without major conditions. These differences continued at follow up with only three children allowed home (table 2). 
Table 5 Summary of legal protection for children

\begin{tabular}{lll}
\hline Protection category & $\begin{array}{l}\text { No of cases (excluding } \\
\text { deaths) initially }\end{array}$ & $\begin{array}{l}\text { No at follow up } \\
\text { (mean 24 months) }\end{array}$ \\
\hline All & 120 & 111 \\
On child protection register & 108 & 35 \\
On care order or interim care order & 60 & 50 \\
Emergency protection order & 26 & 0 \\
\hline
\end{tabular}

Table 6 Protection of children suffering direct harm

\begin{tabular}{lllc}
\hline Category & $\begin{array}{l}\text { No with care order at } \\
\text { follow up (mean 24 } \\
\text { months) }\end{array}$ & $\begin{array}{l}\text { No without care order } \\
\text { at follow up (mean 24 } \\
\text { months) }\end{array}$ & Total \\
\hline Abuse involving direct harm & 44 & 28 & 72 \\
Abuse not involving direct harm & 6 & 33 & 39 \\
Total & 50 & 61 & 111 \\
\hline
\end{tabular}

Table 7 Protection of younger children

\begin{tabular}{lllc}
\hline Category & $\begin{array}{l}\text { Care order at follow up } \\
\text { (mean 24 months) }\end{array}$ & $\begin{array}{l}\text { No care order at follow } \\
\text { up (mean 24 months) }\end{array}$ & Total \\
\hline No over 5 & 5 & 20 & 25 \\
No under 5 & 45 & 41 & 86 \\
Total & 50 & 61 & 111 \\
\hline
\end{tabular}

Five of the 44 non-accidental poisoning victims died. The 39 surviving children were also treated significantly differently from the main body of cases of Munchausen syndrome by proxy in respect of placement: only eight were allowed to return home without major conditions. The differences in placement between suffocation and poisoning and the main cohort were highly significant $(\mathrm{p}<0.0001$; table 1$)$.

DIFFERENCES IN PLACEMENT

We compared the initial placement in all the children who had suffered direct physical harm with those who had not. We defined direct physical harm to include cases of suffocation, poisoning, and Munchausen syndrome by proxy with direct harm. We excluded those who suffered only iatrogenic harm as a result of a false story. The children suffering direct harm were less likely to have returned home $(p<0.01$; table 1). Younger children were also more likely to be protected by removal from the home $(\mathrm{p}<0.01$; table 3$)$. Eleven children who had suffered suffocation (three cases) or poisoning (eight cases) were living at home without major conditions.

MORBIDITY AND MORTALITY IN FOLLOW UP PHASE Paediatricians reported that 27/111 (24\%) of the original children (surviving index cases) were still experiencing symptoms or signs as a direct consequence of the original abuse at follow up. Seventeen had behaviour problems, 10 physical problems, and $13(12 \%)$ were disabled. No child had died as a result of abuse since the initial study.

LEGAL PROTECTION OF CHILDREN

A summary of the legal protection for children is shown in tables 5-7. Although 108 of 120 surviving victims $(90 \%)$ were included on a child protection register at the initial case conference, this had significantly fallen to $32 \%$ $(35 / 111)$ at the time of follow up $(\mathrm{p}<0.001)$.

An emergency protection order or the equivalent in Scotland and Ireland was made in respect of 26 children (22\%) as part of the ini- tial child protection process. These children and 34 other surviving children (60 of 120) were placed under a legal order for protection after the initial investigation. There was a fall at follow up to 50 of 111 (45\%): not a significant difference. Orders were significantly more likely to be made when there had been direct harm to the child and if the child was under 5 years old $(\mathrm{p}<0.01$; tables 6 and 7$)$.

At the time of follow up, prosecution had been pursued in $34(29 \%)$ of cases. Twenty four of these 34 perpetrators $(71 \%)$ were convicted. Of the perpetrators of suffocation, for whom information was available, significantly more prosecutions $(\mathrm{p}<0.01$; table 8$)$ were pursued than for the cohort as a whole. The conviction rate was similar: $15 / 19(79 \%)$. All of the index cases diagnosed by covert video surveillance for whom follow up information was available (six cases) resulted in successful prosecution of the perpetrator.

RISKS OF FURTHER ABUSE WITH MUNCHAUSEN SYNDROME BY PROXY

Of the 111 children followed up, 30 of 39 with no physical harm from Munchausen syndrome by proxy were allowed home unconditionally: five of them were reabused. In two cases the reabuse was further Munchausen syndrome by proxy and in three cases emotional abuse. These cases represent a reabuse rate of $17 \%$ for children suffering Munchausen syndrome by proxy with no physical harm returned home over the period of the study (8500/100 000 per year of follow up). Clearly these were the children with fewer adverse social factors and who had suffered less serious abuse. There were 13 cases of Munchausen syndrome by proxy with physical harm (excluding suffocation and poisoning). Five children were allowed home unconditionally and none was reabused. Four were allowed home with some conditions of whom one was physically abused.

\section{RISKS OF FURTHER ABUSE WITH}

NON-ACCIDENTAL SUFFOCATION

Only three of 26 children with suffocation ascertained at follow up were allowed home unconditionally during the follow up phase, one of whom was reabused (physical abuse). Five were allowed to live with relatives during the follow up period of whom one was abused (emotional). Five out of the 26 were allowed home conditionally (perpetrator excluded) of whom one was abused (emotional and neglect).

To further estimate the likely reabuse rate for suffocation children as a whole, we reexamined our data on siblings. There were 18 suffocation children with siblings. At the time

Table 8 Prosecution of perpetrators

\begin{tabular}{ll}
\hline Category & $\begin{array}{l}\text { No of cases at follow } \\
\text { up (mean 24 months) } \\
\text { (total 111 cases) }\end{array}$ \\
\hline No prosecuted & 34 \\
No successfully prosecuted & 24 \\
No prosecuted for suffocation & 19 \\
No successfully prosecuted for & 15 \\
$\quad$ suffocation & \\
\hline
\end{tabular}


of diagnosis in four families siblings had already died (two of sudden infant death syndrome and two of suffocation abuse); five further children were also abused. We believe the two cases of sudden infant death were very likely to have been abused. This means that in $50 \%$ of the families with siblings there was the likelihood of previous abuse, some of it fatal. These data must mean that reabuse rates are likely to be very high in non-accidental suffocation.

RISKS OF FURTHER ABUSE WITH

NON-ACCIDENTAL POISONING

None of the eight non-accidental poisoning cases allowed home suffered reabuse. However if we re-examine previous abuse in siblings at the time of diagnosis there were 22 families with 41 siblings. In four of these 22 families, five siblings had died: four of definite abuse. In a further five families there had been non-fatal abuse. This means that in $40 \%$ of the families with siblings there was the likelihood of previous abuse, some of it fatal. This suggests that risks of reabuse are very high but perhaps not as high as after suffocation.

ABUSE OF SIBLINGS SINCE INITIAL STUDY

Of the 111 families followed up, 75 families contained 145 surviving siblings. Ten new siblings were born in the follow up phase of whom two $(20 \%)$ were abused, one by physical abuse and one suffered non-organic failure to thrive (all abuse as defined by responding paediatrician). Both were siblings of cases of Munchausen syndrome by proxy without physical harm. Fourteen siblings in nine $(12 \%)$ families had suffered further abuse since the initial study. Abuse was not "true to type", with two cases of Munchausen syndrome by proxy, one poisoning, four physical abuse, two sexual abuse, and five who suffered a combination of emotional and physical abuse and neglect. There were no further cases of sudden infant death in cases or siblings during the follow up period.

\section{Discussion}

This spectrum of child abuse is rare, with approximately 64 cases per year in the British Isles. ${ }^{1}$ The degree of physical abuse varies from severe to none, some cases involving only emotional or iatrogenic abuse, and the different types of abuse overlap considerably. This study attempts to clarify some key medium term outcomes. We acknowledge that the method of study, being anonymised and based on information supplied by paediatricians, will result in underascertainment of subsequent abuse. In particular, abuse of siblings and more subtle forms of emotional abuse are probably under reported.

Our findings indicate that child protection agencies respond most decisively to those cases involving physical abuse, and younger children, with greater use of court orders and less likelihood of maintaining the family intact. This could also be interpreted as statutory agencies placing more emphasis on protecting children from physical injury than more subtle emo-

\section{Key messages}

- None of the cases originally reported as Munchausen syndrome by proxy were found to have had genuine illness

- Evidence from abuse in siblings suggests that in half the families with a child with suffocation there would be further abuse, some fatal

- Evidence from abuse in siblings suggests that in $40 \%$ of the families with a child with non-accidental poisoning there would be further abuse, some fatal

- Even in the cases of Munchausen syndrome by proxy without physical harm allowed home, $17 \%$ were reabused in a two year follow up period

- Cases involving direct harm (including suffocation or poisoning) and younger victims were less likely to have been rehabilitated with their families

- A quarter of all victims had ongoing morbidity as a result of their abuse

- Follow up of victims and their families by a paediatrician is essential

tional abuse. This suggests, however, that agencies do not adopt a reflex response to the diagnosis of Munchausen syndrome by proxy but a measured reaction to the perceived severity of abuse. This is broadly in keeping with our view that, rather than relying upon labels, the exact nature of the abuse should always be described in detail. This places it in context and assists child protection. The finding that abuse involving direct harm to the child is associated with a diminished likelihood of successful rehabilitation suggests that importance is attached to this by child protection agencies. They may also have difficulty in deciding other strategies to intervene progressively and safely if the risk is one of suffocation or poisoning. This is understandable, but the importance of emotional abuse should not be underestimated, even in cases where no physical injury has been inflicted.

The overall frequency of interventions such as care proceedings and accommodation of children is high, reflecting the severity of the abuse in many cases. This contrasts with the overall situation in the UK, where $96 \%$ of children believed to have been abused stay in the parental home, while of those removed from parental care, over two thirds are returned home within six months. ${ }^{8}$ Suffocation in particular is likely to result in the child being separated from the perpetrator.

Despite the high intervention rate, at the time of study a third of victims were still presumably thought to be at risk of abuse. They were included on the local authority social services child protection register, and almost half were still subject to a court order. It is likely that with longer follow up some of these orders would be discharged, but the 
extent to which legal action is required in these cases is impressive.

This study has confirmed that the risk of reabuse in these children is high if they remain unprotected. There appears to be a gradation of risk with the highest in suffocation and the lowest in Munchausen syndrome by proxy without physical harm. The risks of reabuse in all forms of this condition are serious however.

The morbidity of survivors was high and emphasises the serious nature of the abuse. We made no direct measurement of emotional morbidity and this has almost certainly been underestimated. Sibling abuse was more common than reabuse of index children themselves. This suggests that siblings are being inadequately protected by the child protection process and that greater emphasis should be placed on protection of these children rather than waiting for firm evidence of individual abuse.

The ongoing morbidity, further abuse of index cases and harm to siblings all demand a very cautious approach in child protection. Reintroduction to the home should be considered only if the circumstances are especially favourable.

There also needs to be paediatric follow up of the family, especially when the child remains in the care of the perpetrator. This would usually be by the paediatrician who made the diagnosis and is most familiar with the abuse, or by a specialist in child protection. Parents, especially if denying the abuse, may not favour this, in which case it should be included in the child protection plan and ensured by the social services team. We should recognise that subsequent abuse can take virtually any form, including emotional abuse, and be prepared to respond vigorously where this is identified.

As with most types of child abuse, prosecution of perpetrators is the exception, but the overall successful prosecution rate of $20 \%$ (24/ 118 ) is much greater than the $0.5 \%$ quoted for all child protection referrals. ${ }^{8}$ Prosecution is logical where significant harm has been done to the child and there is sufficient evidence to prove guilt beyond reasonable doubt. In some cases it may assist in managing child protection or, arguably, is "therapeutic" for the perpetrator. However, prosecution should not be seen as a prerequisite to child protection, and many children can be adequately protected without it. We would reinforce the comments of the British Paediatric Association working party on evaluation of suspected imposed upper airway obstruction which suggest that: "When there is a very high risk, children should not be exposed to danger simply to achieve a criminal standard of proof".

Covert video surveillance is usually performed in conjunction with the police. Although the numbers are small, cases diagnosed thereby are associated with a high prosecution rate. This is presumably because covert video surveillance provides quality evidence and because suffocation is a serious problem. Without covert video surveillance a high proportion of suffocation victims were protected effectively.

We conclude that this spectrum of abuse includes many severe cases, has long term repercussions for many victims, and commonly requires disruption of the family and/or court orders to protect the child. Children and siblings who remain in the care of the perpetrator after the initial investigation have high morbidity and considerable risk of further abuse. Vigilant medical surveillance is advisable, with a decisive response by statutory agencies when further abuse is likely.

We thank the staff of the BPSU (now part of the Royal College of Paediatrics and Child Health), particularly Richard Lynn, for their help and advice. We are grateful to the Department of Health, the Welsh Scheme for Health and Social Research, and the Catherine Jenkins Trust for financial assistance, and to Heather O'Connell, Dr Tim Ferguson, Zoe Guildea, and Mandy Jones for assistance at various stages in the project. Most importantly we thank fellow paediatricians who gave so generously of their time and help throughout.

1 McClure RJ, Davis PM, Meadow SR, et al. Epidemiology of Munchausen syndrome by proxy. Arch Dis Child Munchausen synd

2 Schreier HA, Libow JA. Hurting for love: Munchausen by proxy syndrome. New York: Guildford Press, 1993.

3 Bools CN, Neale BA, Meadow SR. Follow up of victims of fabricated illness (Munchausen syndrome by proxy). Arch Dis Child 1993;69:625-30.

4 Samuels MP, Southall DP. Munchausen syndrome by proxy. Br f Hosp Med 1992;47:759-62.

5 Meadow SR. Management of Munchausen syndrome by proxy. Arch Dis Child 1985;60:385-93.

6 Neale B, Bools C, Meadow SR. Problems in the assessment and management of Munchausen syndrome by proxy abuse. Children and Society 1991;5:324-33.

7 McGuire TL, Feldman KW. Psychologic morbidity of children subjected to Munchausen syndrome by proxy. Pediatdren subjected to M
rics $1989 ; 83: 289-92$

8 Meadow R, ed. $A B C$ of child abuse. 3rd Ed. London: BMJ Publishing Group, 1997.

9 British Paediatric Association. Report of a working party on evaluation of suspected imposed upper airway obstruction. London: BPA (now the Royal College of Paediatrics and Child Health), 1994. 